\title{
Extent of Surgical Injury Is Associated with Rate of Enoxaparin Metabolism: An Examination of Anti-Factor Xa Levels in Lower Extremity Free Flap Patients
}

\author{
Madison Hunt, BA ${ }^{1}$ Christopher J. Pannucci, MD, MS ${ }^{1,2}$ \\ ${ }^{1}$ Division of Plastic Surgery, University of Utah, Salt Lake City, Utah \\ 2 Division of Health Services Research, University of Utah, Salt Lake \\ City, Utah \\ Address for correspondence Christopher J. Pannucci, MD, MS, \\ Division of Plastic Surgery, University of Utah, 30 North 1900 East, \\ 3B400, Salt Lake City, Utah 84132 \\ (e-mail: Christopher.Pannucci@hsc.utah.edu).
}

J Reconstr Microsurg Open 2017;2:e26-e28.

Venous thromboembolism is a significant cause of morbidity and mortality among surgical patients. ${ }^{1}$ Administration of a once daily or twice daily dose of enoxaparin during the perioperative period is an accepted method to prevent this life- or limb-threatening complication. ${ }^{2,3}$ However, recent studies examining multiple surgical populations have shown that a standard, "one size fits all" dose of enoxaparin does not produce sufficient levels of anticoagulation to prevent deep vein thromboembolism or pulmonary embolism in many patients. ${ }^{4-7}$ Studies in burn patients have shown that the total body surface area (TBSA) burned is associated with rapidity of enoxaparin metabolism; patients with larger TBSA required higher doses of enoxaparin. ${ }^{4,6}$ This is because extensive cutaneous injury produces a systemic inflammatory effect that increases drug metabolism. ${ }^{4}$ Prior work in plastic and reconstructive surgery patients has shown that increased total body surface area surgically injured (TBSI), quantified with a Lund-Brower Chart, is associated with lower anti-factor Xa levels (aFXa); aFXa is a marker of enoxaparin activity and quantifies extent of anticoagulation. However, comparisons between patients have many confounders. The following case series examines the effect of TBSI on enoxaparin metabolism, using free flap patients as their controls. Lower extremity trauma patients who require initial debridement and later free flap surgeries can demonstrate how an increased TBSI may impact enoxaparin metabolism.

\section{Case 1}

A 53-year-old male marathoner and cyclist with a body mass index of $20.9 \mathrm{~kg} / \mathrm{m}^{2}$ presented with an extensive full-thickness wound over the lateral lower leg and ankle (-Fig. 1A).
He underwent surgical debridement creating a 2\% TBSI wound (-Fig. 1B). The patient was started on enoxaparin $40 \mathrm{mg}$ once daily on postoperative day zero. He was enrolled in the University of Utah's clinical trial examining enoxaparin metabolism using aFXa levels (clinicaltrials.gov NCT02411292). aFXa levels were drawn as per the study protocol, and steady state peak aFXa was $0.41 \mathrm{IU} / \mathrm{mL}$. This value was within the appropriate range of 0.3 to $0.5 \mathrm{IU} / \mathrm{mL}$; patients in this range are considered to have blood thin enough to minimize the risk of venous thromboembolism (VTE). ${ }^{5,7-9}$ Based on our established dose-adjustment algorithm for patients who receive once daily enoxaparin, ${ }^{5}$ no dose adjustment was made.

On postoperative day 4, the patient returned to the operating room for debridement and wound coverage using a left parascapular flap-anastomoses were performed endto-side to the anterior tibial artery and end-to-end with two antegrade anterior tibial venae comitantes (- Fig. 1C). During this operation, the patient's TBSI increased to $6 \%$. After surgery, the patient again received $40 \mathrm{mg}$ of enoxaparin daily per the study protocol. Steady-state peak aFXa was $0.21 \mathrm{IU} / \mathrm{mL}$, and this level was below the appropriate VTE prophylaxis target level of 0.3 to $0.5 \mathrm{IU} / \mathrm{mL}$. The enoxaparin dose was increased to $50 \mathrm{mg}$ once daily and repeat steady state peak aFXa was $0.44 \mathrm{IU} / \mathrm{mL}$. He was discharged on postoperative day 7 . The patient had no thromboembolic or bleeding events at 90 days and was back to cycling training at 6 months (-Fig. 1D).

\section{Case 2}

A 54-year-old woman with a body mass index of $17.8 \mathrm{~kg} / \mathrm{m}^{2}$ was referred for orthoplastic management of a Gustillo

Copyright @ 2017 by Thieme Medical

Publishers, Inc., Inc., 333 Seventh Avenue, New York, NY 10001, USA Tel: +1(212) 584-4662.
License terms

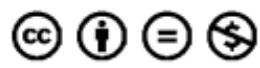

received

November 15, 2016

accepted after revision

February 21, 2017
DOI http://dx.doi.org/

10.1055/s-0037-1601446 ISSN 2377-0813. 


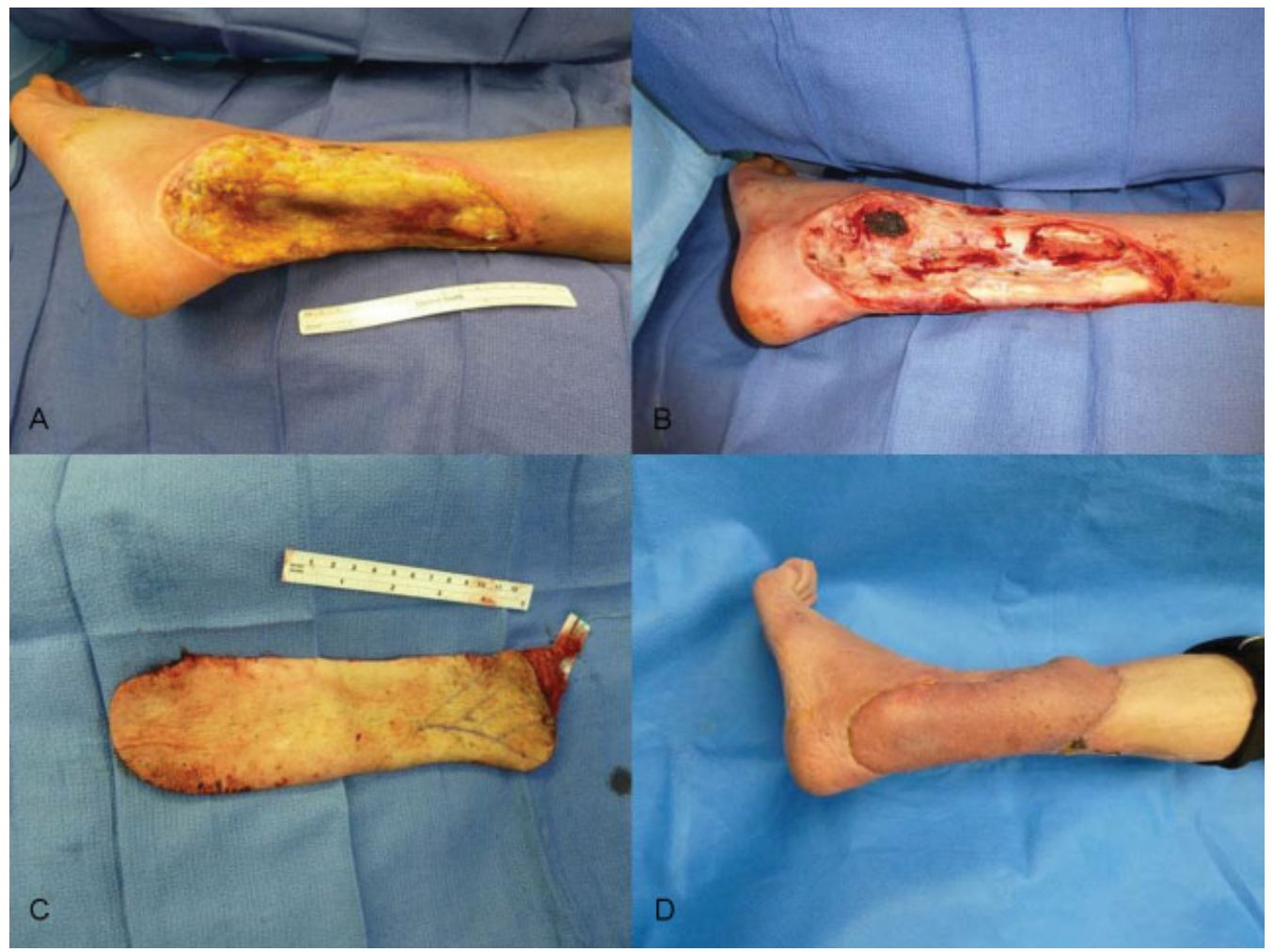

Fig. 1 (A) Defect before initial debridement; (B) defect after initial debridement; (C) parascapular flap; (D) final soft tissue coverage.

3B fracture with exposed hardware. Upon transfer to the University of Utah, she had a large wound with exposed, denuded tibia, exposed fracture line, and exposed hardware ( - Fig. 2A). She initially underwent surgical debridement, and a TBSI of $2 \%$ was created (-Fig. 2B). The patient was started on enoxaparin at $40 \mathrm{mg}$ once daily on postoperative day 0 . Steady-state peak aFXa level was $0.55 \mathrm{IU} / \mathrm{mL}$. The peak aFXa level demonstrated therapeutic levels

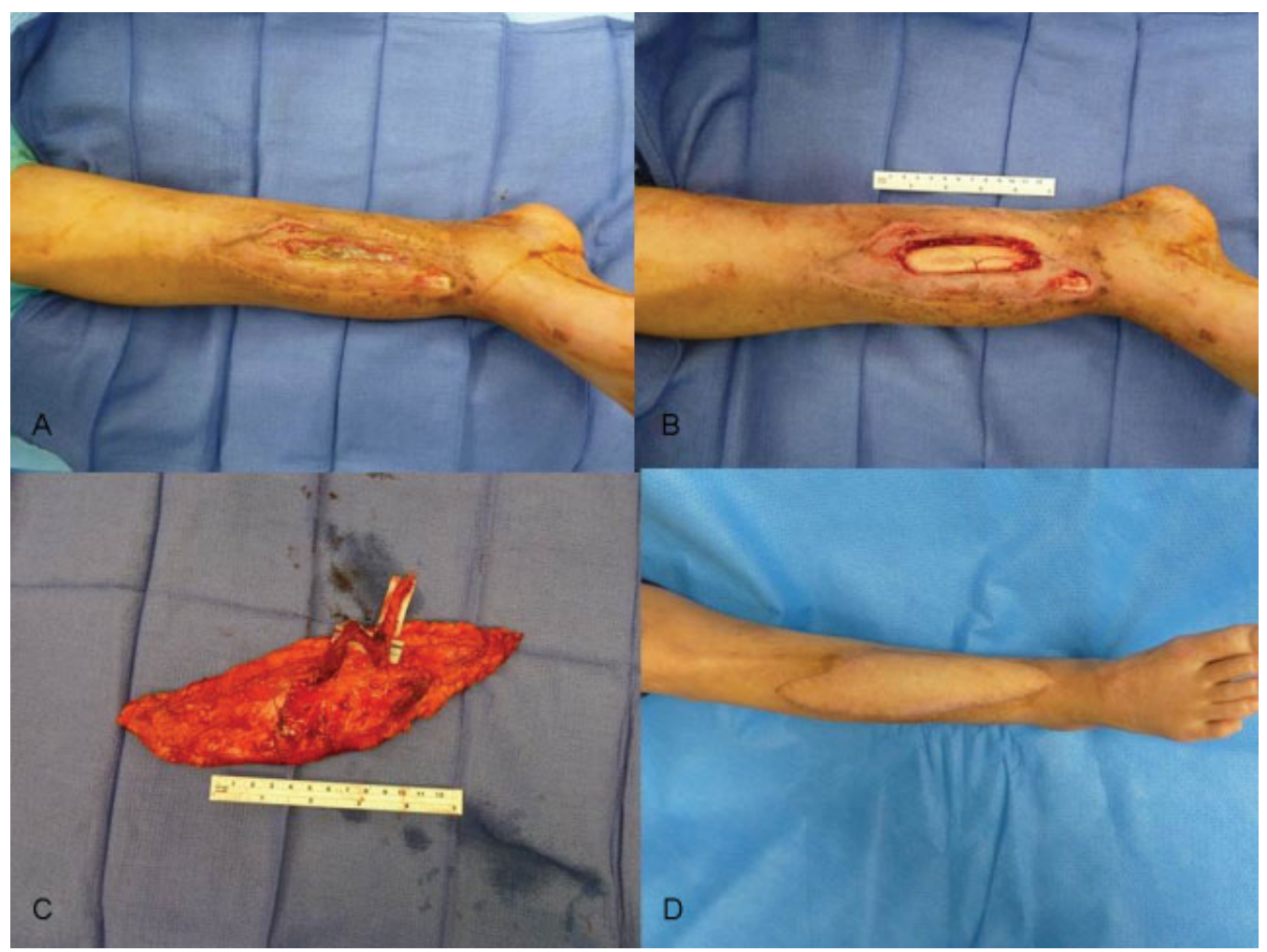

Fig. 2 (A) Defect before initial debridement; (B) defect after initial debridement; (C) two perforator ALT flap; (D) final soft tissue coverage. ALT, anterolateral thigh. 
(aFXa $>0.5 \mathrm{IU} / \mathrm{mL}$ ) of anticoagulation, and her dose was decreased to $30 \mathrm{mg}$ daily. On postoperative day 4 , a two perforator anterolateral thigh flap was used to provide wound closure with an end-to-end anastomoses to the anterior tibial artery and two anterior tibial venae comitantes (-Fig. 2C). This surgery increased the TBSI to $5 \%$. The patient was again placed on enoxaparin $40 \mathrm{mg}$ daily, and steady state peak aFXa level was in range at $0.45 \mathrm{IU} / \mathrm{mL}$. The patient had no thromboembolic or bleeding events at 90 days. She was discharged on postoperative day 7 and had no issues at 1-year follow-up (-Fig. 2D).

\section{Discussion}

Patients in this series are in the unique position of being able to act as their control to compare enoxaparin metabolism in response to surgical procedures of different magnitude. In these patients, increased extent of the surgical injury and downstream inflammation was the only major change that may have altered their physiology within the 7-day study period. Previous studies have examined the impact of gross weight and renal function as factors that can affect enoxaparin metabolism. ${ }^{2,6}$ While TBSI has been associated with aFXa levels in the past, ${ }^{5}$ the between-patient comparisons currently available are vulnerable to confounding. The inpatient comparisons made in this study suggest that increased TBSI may make enoxaparin metabolism more rapid, and further suggests that real-time aFXa monitoring and dose adjustment may minimize VTE risk in free flap patients.

In agreement with previous studies, this idea supports the idea that a "one size fits all" enoxaparin dosing regimen may not be ideal for individual patients and demonstrates the utility of real-time aFXa level monitoring and dose adjustment. ${ }^{5}$ This study also highlights the importance of reassessment of VTE risk during hospitalization. Additional risk factors may be acquired during hospitalization, and the effectiveness of prophylaxis strategies may change based on patient-level factors. ${ }^{10}$ This case series cannot definitively explain the mechanism behind these changes. However, it is worth noting that patients with larger thermal injuries develop hyperdynamic changes at 48 hours after injury (which corresponds to the time when peak aFXa levels are drawn) that may increase drug metabolism and drug clearance. While similar changes may be occurring amongst free flap reconstruction patients, further research is needed to identify the mechanism behind observed alterations in enoxaparin metabolism.

\section{References}

1 Office of the Surgeon General (US); National Heart, Lung, and Blood Institute (US). The Surgeon General's Call to Action to Prevent Deep Vein Thrombosis and Pulmonary Embolism. Rockville, MD: Office of the Surgeon General (US; 2008 Available at: https://www.ncbi.nlm.nih.gov/books/NBK44178. Accessed November 4, 2016

2 Berndtson AE, Costantini TW, Lane J, Box K, Coimbra R. If some is good, more is better: An enoxaparin dosing strategy to improve pharmacologic venous thromboembolism prophylaxis. J Trauma Acute Care Surg 2016;81(06):1095-1100

3 Ricci JA, Crawford K, Ho OA, Lee BT, Patel KM, Iorio ML. Practical Guidelines for Venous Thromboembolism Prophylaxis in Free Tissue Transfer. Plast Reconstr Surg 2016;138(05): $1120-1131$

4 Lin H, Faraklas I, Cochran A, Saffle J. Enoxaparin and antifactor Xa levels in acute burn patients. J Burn Care Res 2011;32(01):1-5

5 Pannucci CJ, Rockwell WB, Ghanem M, et al. Inadequate enoxaparin dosing predicts 90-day venous thromboembolism risk among plastic surgery inpatients: an examination of enoxaparin pharmacodynamics. Plast Reconstr Surg 2016. Doi: 10.1097/ PRS.0000000000003159

6 Faraklas I, Ghanem M, Brown A, Cochran A. Evaluation of an enoxaparin dosing calculator using burn size and weight. J Burn Care Res 2013;34(06):621-627

7 Chapman SA, Irwin ED, Reicks P, Beilman GJ. Non-weight-based enoxaparin dosing subtherapeutic in trauma patients. J Surg Res 2016;201(01):181-187

8 Ludwig KP, Simons HJ, Mone M, Barton RG, Kimball EJ. Implementation of an enoxaparin protocol for venous thromboembolism prophylaxis in obese surgical intensive care unit patients. Ann Pharmacother 2011;45(11):1356-1362

9 Pannucci CJ, Prazak AM, Scheefer M. Utility of anti-factor Xa monitoring in surgical patients receiving prophylactic doses of enoxaparin for venous thromboembolism prophylaxis. Am J Surg 2016. Doi: 10.1016/j.amjsurg.2016.08.010

10 Iannuzzi JC, Young KC, Kim MJ, Gillespie DL, Monson JR, Fleming FJ. Prediction of postdischarge venous thromboembolism using a risk assessment model. J Vasc Surg 2013;58(04):1014-1020.e1 